\title{
TRANSFORMASI STRUKTUR BENTUK JARINGAN JALAN DI KAWASAN SIMPANGLIMA KOTA BANDUNG
}

\author{
Syarifah Ismailiyah Al-Athas \\ Program Studi Arsitektur, Fakultas Teknik Sipil dan Perencanaan, Universitas Islam Indonesia \\ lya.alatas@gmail.com
}

\begin{abstract}
ABSTRAK. Studi ini bertujuan untuk menganalisis perubahan bentuk jaringan jalan dan bentukan ruang yang terjadi dalam skala kota Bandung. Secara khusus, studi transformasi ini akan digerakkan pada obyek pertumbuhan jaringan jalan di simpang lima kota Bandung sebagai salah satu penggal Grote Postweg serta pembentukan ruang yang terjadi sebagai akibat pertumbuhan pembangunan ruas jalan dan bangunan di tepiannya. Dengan multi-signifikansinya, ruas jalan ini mengalami berbagai perubahan karakter dan memerlukan strategi konservasi serta peninjauan kembali signifikansi tampak ruang jalan. Studi dimulai dengan paparan singkat tentang signifikansi kawasan Simpanglima Bandung dalam konteks penggal pertama dalam pembangunan Grote Postweg. Data fisik berupa catatan sejarah dan dokumentasi peta jalan serta bangunan di kawasan Simpanglima Bandung selama rentang waktu 1808 sampai dengan 1942 akan menjadi obyek analisis selanjutnya. Kerangka analisis pada studi ini bersumber dari teori transformasi N.J. Habraken yang menempatkan 'bentuk' sebagai wujud keteraturan fisik. Tahap pertama analisis akan dilakukan terhadap data fisik Simpanglima Bandung untuk mensarikan elemen yang akan diamati perubahannya. Analisis kemudian dilanjutkan untuk merumuskan konfigurasi elemen tersebut beserta proses pertumbuhannya. Lebih mendalam lagi pada studi selanjutnya, rentang waktu dipilih untuk membatasi studi pada andil pemerintah kolonial Belanda sebagai agen transformasi dalam pembentukan morfologi simpang lima pada khususnya, dan kota Bandung secara umum dalam konteks kolonialisasi.
\end{abstract}

Kata kunci: transformasi, morfologi, Simpanglima Bandung, keteraturan fisik

ABSTRACT. This study is aimed to analyze the deformation of the road network and the formation of the space in Bandung. In particular, the study of this transformation will be driven on the object of the growth of the road network in the Simpanglima Bandung as one piece of Grote Postweg as well as the formation of space occurs as a result of roads construction growth and buildings on its streetscape. With multi-significance, this road undergone various changes in character and require conservation strategies as well as a review of the significance of visible road space. The study has been begun with a brief description of the significance of Simpanglima Bandung region in the context of the first cut-off in the construction Grote Postweg. Physical data such as historical records and documentation as well as the road map Simpanglima Bandung buildings in the area during the time range between 1808 to 1942 will become an object for further analysis. Framework of analysis in this study comes from the theory of transformation N.J. Habraken who put the 'shape' as a form of physical regularity. The first stage of the analysis will be performed on the physical data Simpanglima Bandung to extract elements that will be observed. Analysis then proceeded to define the configuration of these elements along with the growth process. More deeply in subsequent studies, the time range has been chosen for the study limits the influence of the Dutch colonial government as an agent of transformation in the establishment of Simpanglima morphology in particular, and the city of Bandung in generally in the context of colonization.

Keywords: transformation, morphology, Simpanglima Bandung, physical regularity

\section{PENDAHULUAN}

\section{Simpanglima Bandung sebagai Penggalan Grote Postweg}

Terdapat beberapa jenis jalan raya di Indonesia, dari jalan tol modern hingga jalan trans-daerah. Namun, muka jalan di Indonesia yang berbicara paling penting tentang sejarah kota di Indonesia adalah Jalan Pos Besar di Jawa, disebut Grote Postweg yang dibangun atas perintah Herman Willem Daendels pada rentang masa 1808-1811. Dengan multisignifikansi sejarah, ekonomi, dan arsitektur, ruas panjang jalan ini mengalami berbagai macam perubahan karakter dan memerlukan strategi rinci konservasi serta peninjauan kembali signifikansi tampak ruang jalan yang menghubungkan kota besar seperti Jakarta, Bogor, Bandung, Cirebon, dan Semarang.[6].

Dari ribuan kilometer jalan yang menjadi urat nadi pulau Jawa, penggal jalan Bogor-Cirebon 
dianggap memiliki signifikansi sejarah yang tinggi sebagai penggal Grote Postweg yang pertama kali dibangun pada 1808 [1]. Penggal jalan ini melewati kota Bogor, Cipanas, Bandung, Sumedang, Cirebon.

Pembangunan awal kawasan Simpanglima Bandung sebagai bagian dari Grote Postweg pun diprakarsai oleh Daendels melalui surat perintah tanggal 15 Mei 1810 untuk Bupati Adipati Wiranatakusuma II. Dalam surat tersebut tertulis ibukota Kabupaten Bandung dipindahkan dari Dayeuh Kolot ke sebelah Selatan titik poros Alun-Alun. Perpindahan ibukota Kabupaten Bandung inilah yang akhirnya mendorong pembangunan Jalan Asia-Afrika, Jalan Jendral Sudirman, serta Jalan Jendral Ahmad Yani sebagai penggalan dari Grote Postweg saat ini. Pembangunan jalan-jalan tersebut dilatarbelakangi faktor politik dan pertahanan Belanda, termasuk diantaranya keperluan transportasi pos.

Kehadiran jaringan jalan baru ini pada awalnya berimpitan dan berpotongan dengan jalanjalan lama yang terlebih dahulu ada dan merupakan awal pertumbuhan jaringan jalan baru yang terencana di Bandung. Dari proses penambahan jaringan jalan yang mengikuti pertumbuhan pusat kota baru itulah kemudian Simpanglima Bandung terbentuk.

\section{Fakta Saat Ini}

Simpanglima Bandung merupakan pertemuan lima jaringan jalan yaitu Jalan Asia Afrika dengan arus lalulintas ke arah Barat, Jalan Jenderal Ahmad Yani dengan arus lalulintas ke arah Barat pula, Jalan Jenderal Gatot Subroto dengan arus lalulintas dua arah ke Barat dan Timur, Jalan Sunda bagian Utara serta Jalan Sunda bagian Selatan yang keduanya berarus lalulintas ke arah Utara Simpanglima. Tentang bahu jalan dan keberadaan jalur pedestrian, pada sisi kiri dan kanan Jalan Asia Afrika terdapat jalur pedestrian. Begitu pula dengan Jalan Jenderal A.Yani. Tetapi pada Jalan Sunda dan Jalan Jenderal Gatot Subroto hanya sebagian ruas jalan saja yang dilengkapi jalur pedestrian. Pergerakan sirkulasi kendaraan bermotor dan pergerakan pengguna jalan yang menyeberang jalan ditentukan oleh lampu pengatur lalulintas yang dilengkapi countdown timer. Khusus untuk pejalan kaki, terdapat kesulitan dalam penyeberangan jalan karena singkatnya waktu penyeberangan yang diatur oleh lampu lalulintas.
Dari lima sudut yang ada di Simpanglima Bandung, saat ini hanya tersisa tiga sisi yang terisi bangunan otentik seperti saat awal terbentuknya. Bangunan tersebut adalah bekas Toko Soerabaja yang diperkirakan dibangun pada tahun 1910 di sudut Jalan Gatot Subroto dan Jalan A.Yani, bekas Apotek De Voor Zorg yang diperkirakan dibangun pada tahun 1912 di sudut Jalan Sunda bagian Selatan dan Jalan Asia Afrika, serta ekstensi bekas Toko Singer yang diperkirakan dibangun pada tahun 1930-an di sudut Jalan Sunda bagian Utara dan Jalan Asia Afrika. Ketiga bangunan ini praktis tidak berfungsi dengan baik dan sangat kurang dalam hal perawatan bangunan. Hanya bangunan bekas Toko Soerabaja yang terawat dengan baik. Dua sudut simpang jalan yang lain telah terisi dengan bangunan baru yaitu Wisma Lippo berupa gedung 12 lantai di sudut Jalan Gatot Subroto dan Jalan Sunda bagian Selatan, serta bangunan bengkel berlantai tiga yang mengisi sudut Jalan A.Yani dan Jalan Sunda bagian Utara.

Terdapat bermacam-macam fungsi bangunan di kawasan Simpanglima Bandung, seperti misalnya pertokoan, perkantoran, rumah kediaman, rumah toko, bengkel, warung makan, dan lain-lain. Semua kegiatan ini terdapat pada kelima jalan yang bersatu di Simpanglima Bandung ini.

\section{Aplikasi Teori Transformasi Habraken dalam Perkembangan Simpanglima}

Selain pemaparan historis, teori keteraturan fisik dan transformasi struktur bentuk yang dikemukakan oleh N.J. Habraken dalam bukunya Structure of the Ordinary akan menjadi kerangka analisis dalam studi ini.

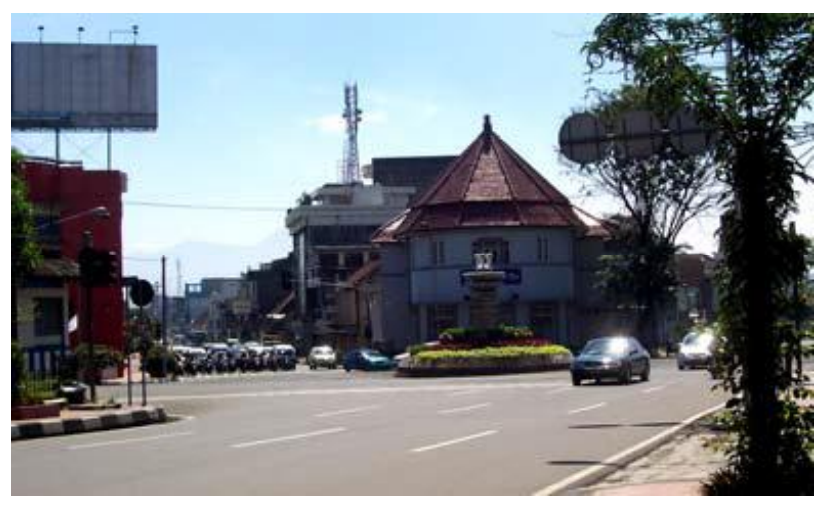

Gambar 1. Bangunan Toko Soerabaja dan Tugu Simpanglima dilihat dari Jalan Asia-Afrika (sumber: Dokumentasi Pribadi, 2010). 


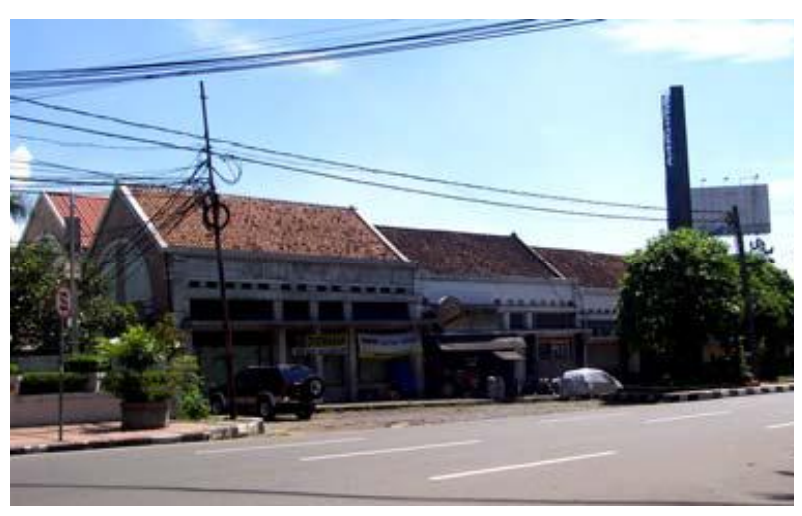

Gambar 2. Bangunan Rumah Toko Ekstensi Toko Singer dilihat dari Jalan Asia-Afrika. Bangunan berkonsep setback terhadap jalan raya (sumber: Dokumentasi Pribadi, 2010).

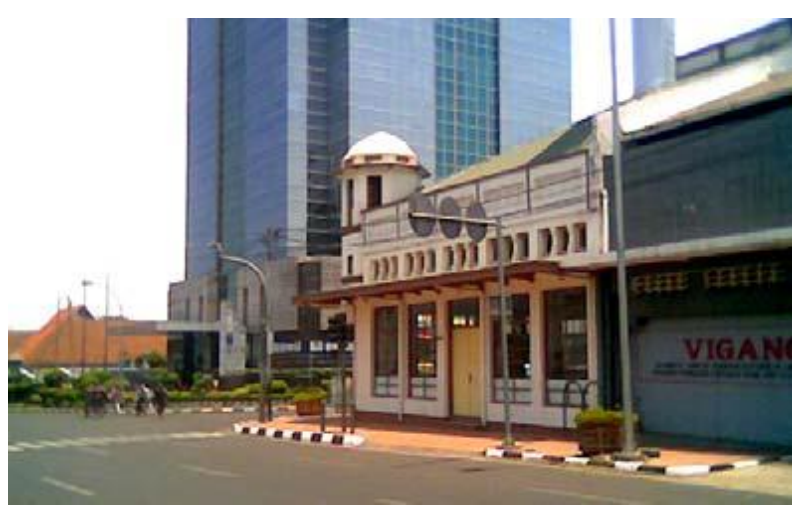

Gambar 3. Bangunan Apotek De Voor Zorg dengan latar Gedung Wisma Lippo dilihat dari Jalan Asia Afrika

(sumber: Dokumentasi Pribadi, 2006)

Menurut Habraken [2], untuk memahami struktur lingkungan, elemen dan konfigurasi harus ditunjuk dengan cara yang berhubungan dengan tindakan agen, dalam hal ini pemerintahan kolonial Belanda. Karena transformasi merupakan hasil dari tindakan agen, hal tersebut menggarisbawahi nilai penting elemen dan konfigurasi di bawah kontrol agen. Kontrol tersebut, pada gilirannya, mendefinisikan unit transformasi apakah akan bergerak pada tataran fisik, ataukah teritori, bahkan lebih jauh lagi dalam tataran budaya. Dalam kasus ini, studi akan digerakkan dalam tataran fisik. Elemen jalan raya, jalur pedestrian, masa bangunan di sepanjang jalan akan diteliti untuk mendapatkan temuan berupa konfigurasi dinamis dari lingkungan binaan. Bentukan jaringan jalan pembentuk Simpanglima Bandung akan ditelaah sebagai konfigurasi yang terus bertumbuh seiring dengan waktu.

Lebih jauh lagi, dalam meneliti bangunan yang mengalami transformasi, kita mengamati sebuah fenomena keunikan hirarki.
Lingkungan binaan terdiri dari level intervensi yang berbeda, yang sebagian besar mengatur apa yang agen lakukan. Interaksi antara agen dapat mempengaruhi dan mengubah hirarki level itu sendiri.

Dari paparan Teori Transformasi Habraken tersebut, nampak jelas bahwa hal-hal yang akan berpengaruh dalam transformasi lingkungan binaan adalah faktor bentukan, struktur, konfigurasi, level, agen, dan kontrolnya. Faktor awal yang akan diaplikasikan dalam analisis transformasi kawasan Simpanglima Bandung adalah faktor fisik berupa bentukan, struktur, serta konfigurasi. Faktor level, agen serta kontrol akan dikemukakan pada studi lanjutan yang membahas peran pemerintah kolonial Belanda sebagai agen dan pengontrol dari transformasi kawasan Simpanglima Bandung tersebut. Dalam rencana lanjutan tentang studi ini, proses uji pun akan dilakukan terhadap postulat Habraken tentang Hubungan Dominansi dan Tingkat Ketergantungan antar level.

"The higher level configuration dominates the lower level; and the later is dependent on the former" [2]

Pada proses uji tersebut nantinya, data sejarah dan dokumentasi tentang bentukan fisik ruang bangunan di sekitar kawasan Simpanglima Bandung akan diperlakukan sebagai konfigurasi level bawah dan jaringan jalan di kawasan Simpanglima Bandung akan diperlakukan sebagai konfigurasi dinamis level atas.

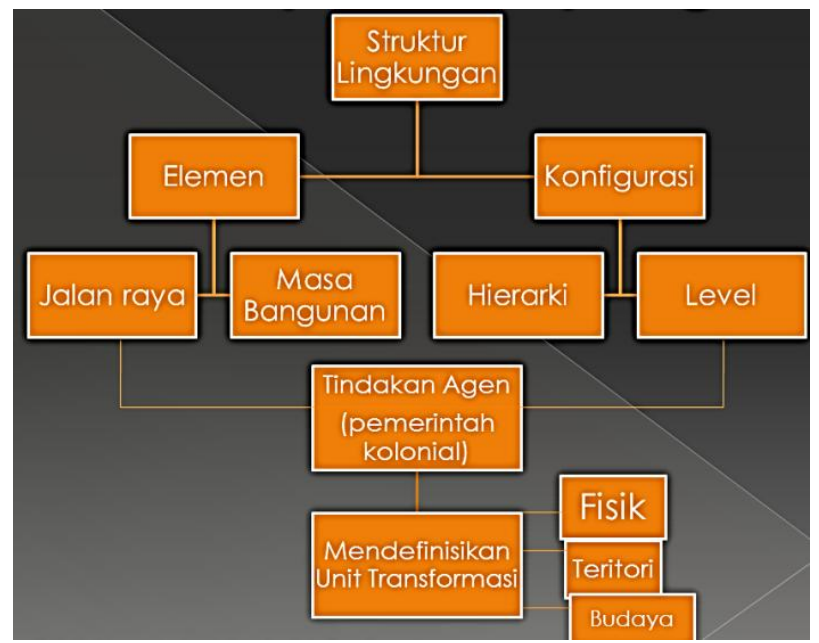

Gambar 4. Aplikasi Teori Transformasi Habraken pada Simpanglima Bandung

(Sumber : Analisa) 


\section{Level Atas: Jaringan Jalan Simpanglima Bandung dari Masa ke Masa}

Seperti telah disebutkan sebelumnya, pada tahun 1808 Daendels membangun ruas jalan Grote Postweg yang melintas di Bandung dengan nama Jalan Jenderal Sudirman, Jalan Asia Afrika dan Jalan A Yani. Lokasi jalan ini ditetapkan atas dasar kekuatan tanah memenuhi syarat, karena disebelah Selatan terdapat rawa-rawa (ranca) yang tidak memungkinkan pembangunan jalan di atasnya. Dalam makalah ini dikaji perkembangan jaringan jalan dan bangunan serta ruang publik yang terbentuk di sekitar Simpanglima Bandung. Seperti lahirnya persimpangan jalan lain di kota Bandung, maka Simpanglima terjadi karena perpotongan jalan lama yaitu Jalan Sunda dan poros utama Jalan Asia Afrika dan Jalan Jenderal A Yani. Akibat perpotongan itu, maka Jalan Sunda terbagi menjadi dua ruas yaitu di sebelah Utara dan di sebelah Selatan Simpanglima.

Pembangunan jaringan jalan kereta api mulai dilakukan pada tahun 1884. Daerah Majalengka, Soreang dan Banjaran saat itu mulai dapat dicapai dengan moda transportasi Kereta Api. Beberapa halte (standplaat) dibangun, diantaranya Halte Cikudapateuh dengan gudang-gudang penyimpanan hasil bumi dari perkebunan Kina di sekitar Bandung. Munculnya halte ini merupakan contoh perkembangan pusat pertumbuhan baru yang mempengaruhi pertumbuhan Simpanglima selain pembangunan Pasar Kosambi, Pasar Tegallega, Pasar Cicadas, dan Pasar Kiaracondong pada kurun waktu 1920-1930. Pada tahun 1889, dibangunlah pabrik senjata (sekarang PINDAD) di lokasi Kiaracondong sebagai hasil pindahan dari lokasi sebelumnya di kota Surabaya. Untuk pemukiman buruhnya, dibangunlah Babakan Surabaya. Atas alasan itu maka dibuatlah Jalan Gatot Subroto, melalui Jalan Ketapang dari Jalan Jenderal A Yani pada tahun 1896. Baru pada kurun waktu tahun 1920-an dibangun jalan yang menghubungkan Jalan Gatot Subroto dengan simpang empat pada saat itu.

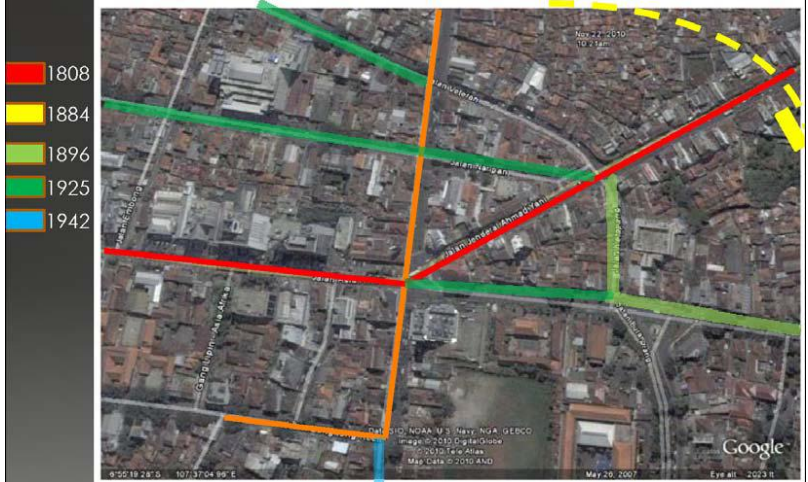

Gambar 5: Pertumbuhan jalan di Simpanglima Bandung. Penggal Grote Postweg tergambar dalam garis warna merah

Sumber: olah data mandiri pada citra Google Earth 2015

\section{Level Bawah: Bangunan di Simpanglima Bandung sebagai Pembentuk Ruang}

Analisis pada level bawah ini dimulai dari bangunan bekas Toko Soerabaja yang terletak di persimpangan Jalan Ahmad Yani dan Jalan Gatot Subroto. Dari dokumen yang dijumpai, bangunan ini mulai dibangun pada tangal 21 Desember 1915. Kemungkinan besar pada pembangunan awal belum menerapkan konstruksi beton karena konstruksi tersebut mulai digunakan di kota Bandung pada tahun 1920 [8]. Kemudian terjadi revisi pada strukturnya yang menggunakan beton, juga penggunaan atap sirap yang diperkirakan dilakukan pada tahun 1920-an pula. Hal itu didasarkan pada argumen bahwa atap Aula Barat Technische Hoogeschool dan atap Gedung Sate yang dibangun pada masa itu pun beratapkan material sirap. Dari penyelesaian tampak, terlihat pintu dan jendela tidak terlindung seperti bangunan lainnya, seakan-akan bangunan ini kurang terencana dengan baik dari segi bukaan. Pembuatan lubang jendela yang timbul kemudian disesuaikan dengan kebutuhan ruang tanpa mempertimbangkan keserasian tampak secara keseluruhan. Pada foto dokumentasi tahun 1935, bangunan tersebut tampak seperti adanya saat ini. Bentuk atapnya belum terkena dampak larangan trotoir sebagai muara air buangan atap seperti pada bangunan Singer, Weston dan bangunan lainnya yang didirikan belakangan. Atas dasar itulah maka penulis memperkirakan bangunan bekas Toko Soerabaja dibangun pada tahun 1900. 


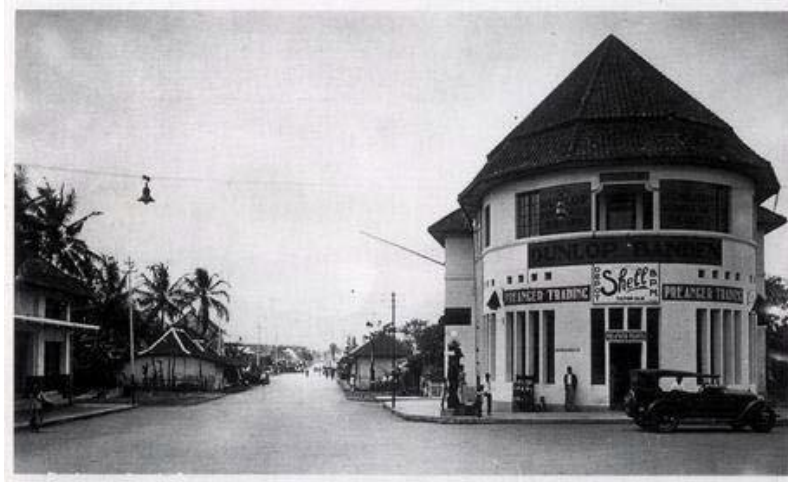

Gambar 6. Tampak Simpanglima dan Toko Soerabaja pada tahun 1935. Tampak di sini Jalan Jenderal Ahmad Yani masih terasa lengang dengan jumlah vegetasi yang cukup signifikan (sumber: Voskuil, 1997)[3]

Pada bangunan di sudut Jalan Sunda dan Jalan Ahmad Yani, tidak tampak pula penyesuaian bentuk atap akibat peraturan larangan air buangan atap (Besluit 1906). Pada data dokumentasi yang penulis dapat, tampak bahwa bangunan ini masih berdiri dengan kokoh pada tahun 1935 dan berfungsi sebagai toko. Bangunan Toko Weston dan Toko Singer direncanakan dibangun menyatu dengan Toko Singer sebagai bangunan utamanya. Bangunan ini dibangun kurang lebih pada tahun 1930-an. Bangunan ini terdiri dari dua lantai dan menggunakan konstruksi beton yang baru mulai digunakan di Bandung saat itu. Di tengah bangunan ini terdapat jalan masuk semacam 'kolong' menuju kompleks bangunan kampung di baliknya. Hal ini menandakan adanya pertimbangan kepentingan sosial dalam pembangunan bangunan ini. Toko Singer dibangun di atas tanah milik pemerintah kolonial Belanda. Kemungkinan, jalan terobos tersebut sudah ada sebelumnya dan bangunan Toko Singer yang menyesuaikan kemudian.

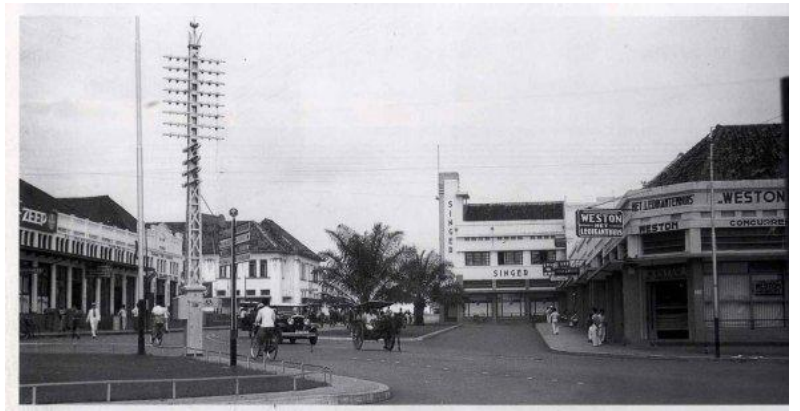

Gambar 7. Tampak Simpanglima pada sisi Toko Singer pada tahun 1935. Tampak di sini Grote Postweg sudah terisi dengan bangunan modern kolonial di sepanjang jalannya, tidak ada lagi rumah beraksen oriental pada persimpangannya dengan Kaca Kaca Wetan

(sumber: Voskuil, 1997)[3]
Tabel 1. Analisis visualisasi transformasi bangunan di Simpanglima Bandung sebagai pembentuk ruang
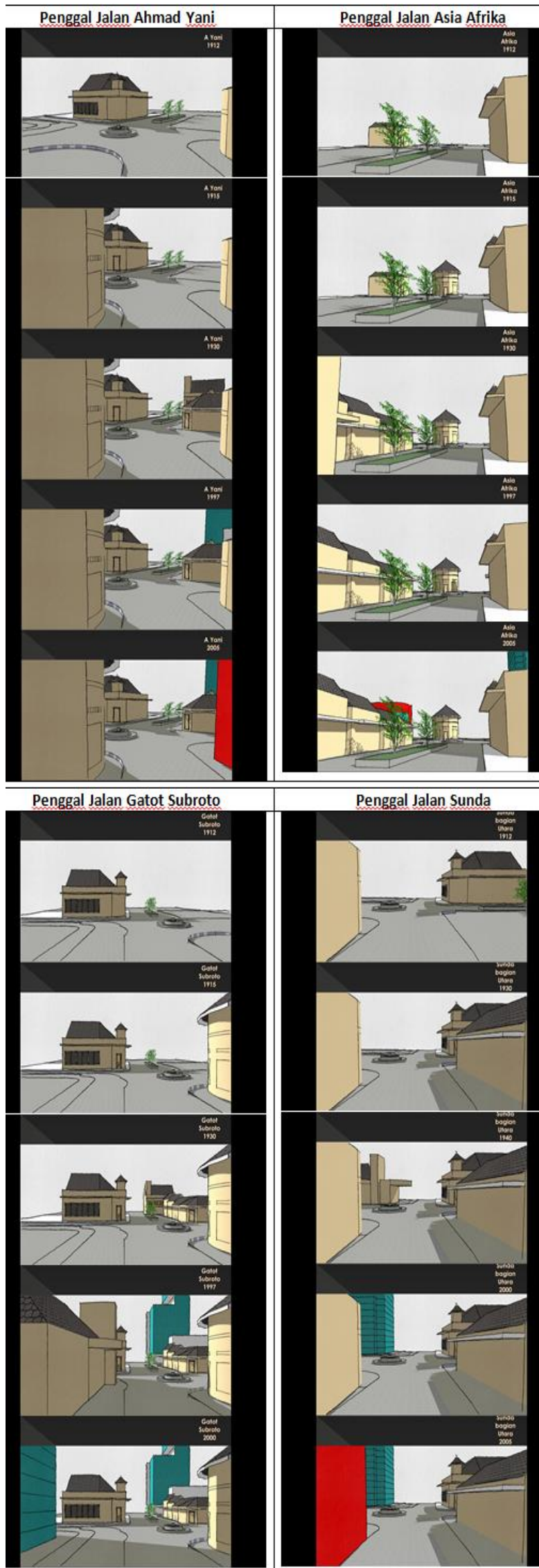


\section{Bandung, Simpanglima Bandung dan Tendensi Pemerintah Kolonial}

Bandung yang saat ini menyandang predikat Ibukota Propinsi Jawa Barat merupakan salah satu kota penting yang ada di Indonesia. Kota yang di awal abad ke-20 nyaris menjadi hoofdstad Hindia Belanda menggantikan Batavia ini memiliki akar sejarah panjang. Rentang perjalanan Bandung sebagai sebuah kota dapat dikatakan dimulai pada tanggal 25 September 1810. Pada tanggal tersebut, Bupati ke-6 Bandung R.A. Wiranatakusumah II (1794-1829) tampil sebagai inisiator pembentukan kota Bandung. Inisiatif Wiranatakusumah II ini secara tidak langsung mendapat akselerasi dari pemerintah kolonial Belanda, melalui bes/uit yang dikeluarkan Gubernur Jenderal H.W. Daendels.

Pada masa-masa awal pembentukannya tidak banyak perkembangan signifikan yang dialami kota Bandung. Barulah setelah Bandung ditetapkan sebagai ibukota Karesidenan Priangan di tahun 1864 menggantikan kedudukan Cianjur. Secara perlahan tapi pasti terjadi perubahan-perubahan yang cukup berarti dalam tampilan kota Bandung. Keberadaan kota Bandung sebagai pusat politik dan pemerintahan Karesidenan Priangan ini kemudian diikuti pula dengan keberadaannya sebagai sentra produksi industry perkebunan besar di Priangan, seperti kopi, teh, kina, dan karet. Untuk itu semua, pembangunan kota Bandung sampai dengan akhir abad ke-19 tampak difokuskan untuk dapat memenuhi berbagai kebutuhan kota Bandung, baik sebagai pusat kegiatan politik, maupun dalam perannya sebagai pusat kegiatan ekonomi di Priangan.

Memasuki abad ke-20, sebuah perubahan besar kembali dialami kota Bandung. Berdasarkan ordonantie tanggal 21 Februari 1906, Bandung memperoleh status wilayah administratif baru sebagai sebuah gemeente. Peresmian sekaligus penetapan Bandung sebagai sebuah gemeente dilakukan oleh Gubernur Jenderal J.B. Van Heutzs pada tanggal 1 April 1906 (Verslag 1919:1). Saat gemeente Bandung didirikan, wilayahnya melingkupi dua buah kecamatan (onderdistrict), yaitu kecamatan Bandung Kulon (Barat) dan kecamatan Bandung Wetan (Timur). Kecamatan Bandung Kulon terbentuk atas 8 desa yaitu Andir, Citepus, Pasar, Cicendo, Suniaraja, Karanganyar, Astana Anyar dan Regol. Kecamatan Bandung Timur terdiri dari 6 desa yaitu Balubur, Kejaksaan, Lengkong, Kosambi, Cikawao dan Gumuruh.
Sejak status gemeente disandang, tidak pelak lagi Bandung memainkan peran yang semakin penting dalam percaturan politik dan ekonomi pemerintah kolonial Belanda. Bandung pun hadir sebagai tempat peristirahatan orangorang Europeesche, khususnya bangsa Belanda sendiri. Berbagai sarana dan prasarana penunjang bagi sebuah kota modern kemudian banyak dibangun di kota Bandung. Keberadaan Bandung sebagai ibukota propinsi Jawa Barat kemudian pada akhirnya membawa akselerasi pada perkembangan pusat ekonomi kota Bandung.

Perubahan fisik paling awal yang terjadi di kota Bandung pada awal abad ke-20 lebih diarahkan pada upaya pengadaan sarana dan prasarana fisik yang dapat digunakan untuk pemerintahan gemeente. Namun demikian, karena satu dan lain hal, keinginan untuk segera memiliki sebuah kantor pemerintahan gemeente yang representatif ini tidak dapat langsung direalisasikan. Untuk itu, pada masa pemerintahan awal gemeente Bandung, sebagai kantor gemeente dipilihlah bagian atas dari gedung yang pernah menjadi toko Sumur Bandung di Grote Postweg (sekarang disebut jalan Asia Afrika). Beberapa waktu kemudian barulah pindah ke Gedong Papak (kantor Pemerintah Kota Bandung sekarang), yakni sebuah bangunan yang berdiri dia atas lahan bekas gudang kopi milik Andries de Wilde [4].

Gedong Papak ini dipilih karena letaknya yang strategis kemudian ditetapkan sebagai kantor tetap pemerintahan gemeente Bandung. Penataan terhadap Gedong Papak sebagai kantor pemerintahan gemeente Bandung bisa dikatakan dilakukan secara bertahap sebelum dapat benar-benar menjadi gedung pemerintahan yang representatif. Setelah pemerintahan gemeente memperoleh gedung yang benar-benar representatif, penataan kota Bandung secara keseluruhan kemudian mendapat perhatian yang benar-benar serius dari pemerintah gemeente. Rencana dan keinginan pemerintah gemeente untuk menjadikan kota Bandung sebagai kota modern seakan-akan mendapat dorongan yang lebih kuat ketika dalam dasawarsa kedua abad ke-20 atau semasa pemerintahan Gubernur Jenderal J.P. Graaf Van Limburg Stirum (1916-1921) timbul ide dan gagasan untuk memindahkan ibukota Hindia Belanda dari Batavia (Jakarta) menuju ke kota Bandung [5].

Rencana perpindahan ibukota tersebut dilatarbelakangi oleh setidaknya tiga alasan. 
Pertama, alasan kondisi kesehatan kota Batavia sebagai kota pantai, sebagaimana disebutkan oleh H.F Tillema dalam studinya tentang kesehatan di kota-kota pesisir pantai Utara Jawa pada tahun 1916. Kedua, alasan pertahanan yang juga melandasi dibangunnya Grote Postweg dan ketiga adalah alasan potensi perkembangan aktivitas ekonomi Bandung yang dinilai cukup tinggi. Dalam perkembangannya kemudian, agar pembangunan fisik di kota Bandung dapat tertata dengan baik dan selaras dengan rencana kota Bandung sebagai ibukota Hindia Belanda, pemerintah gemeente Bandung bersama-sama dengan pemerintah pusat membentuk sebuah tim perencanaan gabungan yang terdiri dari militer (zeni), Departemen Pekerjaan Umum dan Dinas Teknik Kotapraja [4].

Tim ini dipimpin oleh V.L. Sloors, seorang pensiunan militer dari kesatuan zeni dan beranggotakan G.Hendriks, E.H.de Roo dan J Gerber. Mengingat tugas tim perencana gabungan lebih difokuskan pada upaya menjadikan kota Bandung sebagai ibukota Hindia Belanda, maka agar rencana pengembangan kota Bandung yang sebelumnya telah dipersiapkan pemerintah gemeente tidak terbengkalai serta dapat tetap berjalan sesuai dengan yang telah direncanakan, maka pemerintah gemeente Bandung pada awal dasawarsa ketiga abad ke-20 atau tepatnya pada tahun 1921 membentuk sebuah komisi pembangunan kota Bandung. Tugas komisi yang diberi nama Komisi Rencana Perluasan Wilayah Gemeente Bandung ini antara lain adalah membenahi wajah kota, termasuk didalamnya menata dan menghijaukan kota dengan taman-taman kota agar Bandung benar-benar layak untuk menjadi ibukota Hindia Belanda. Melalui komisi inilah pada akhirnya lahir sebuah rencana pembangunan Bandung yang benarbenar terpadu.

Rencana pengembangan kota Bandung produk Thomas Karsten ini kemudian dikenal dengan nama Plan Karsten. Meskipun pada akhirnya rencana menjadikan Bandung sebagai ibukota Hindia Belanda tidak menjadi kenyataan, sedikit banyaknya Bandung tetap dapat merasakan manfaat dari rencana tersebut. Berbagai bangunan yang cukup megah yang semula dipersiapkan sebagai gedung perkantoran pemerintah pusat dibangun di Bandung. Diluar hal tersebut dan optimalisasi jalur kereta api, optimalisasi lain bagi perhubungan darat dilakukan dengan meningkatkan serta memperbaiki kualitas jalan-jalan yang ada di kota Bandung. Upaya perbaikan jalan raya ini dilakukan secara intensif sejak tahun 1909. Pada awalnya diperbaiki lima buah jalan, yaitu Merdekalioweg (kini Jalan Wastukencana), Kerklaan (kini Jalan Jawa), Parklaan (kini Jalan Merdeka), Lembangweg (kini Jalan Cihampelas dan Jalan Setiabudi), serta Dagoweg (kini Jalan Ir H Juanda). Perbaikan jalan dilakukan dengan memperkeras jalanjalan tersebut dengan pasir dan kerikil. Setelah perbaikan dan peningkatan kualitas kelima jalan tersebut, beberapa waktu kemudian juga dilakukan perbaikan dan peningkatan kualitas jalan-jalan lainnya yang ada di kota Bandung, termasuk diantaranya pelebaran jalan seperti Grote Postweg, Gardujatiweg, Pasarbaruweg dan Tamblongweg [7].

Status gemeente bagi kota Bandung sedikit banyak memperlihatkan adanya sosok modern sebuah kota, yang di dalamnya menjanjikan berbagai macam fasilitas menarik bagi penduduk. Daya tarik kota Bandung sebagai sebuah gemeente ini pada akhirnya berpengaruh besar terhadap peningkatan konsentrasi penduduk yang tinggal dan menetap di kota Bandung. Akibatnya, Bandung yang pada pertengahan abad ke-19 hingga beberapa waktu setelah menyandang status sebagai ibu kota karesidenan Priangan masih menyandang sebutan sebagai daerah yang jarang penduduk (sparsely populated region) berubah menjadi daerah yang padat penduduk (densely populated region) saat memasuki abad ke-20.

Singkat kata dapat dikatakan bahwa tidak ada peningkatan jumlah penduduk Eropa di kota Bandung yang melebihi peningkatan pada tahun 1920. Demikian pula halnya dengan penduduk pribumi dan Cina. Fenomena perubahan lain yang cukup menarik berkaitan dengan penduduk kota Bandung ialah fenomena perubahan pada perbandingan jumlah penduduk berkebangsaan Eropa dengan penduduk berkebangsaan Cina. Bila pada tahun pertama kota Bandung menjadi gemeente jumlah penduduk berkebangsaan Cina lebih banyak daripada jumlah penduduk berkebangsaan Eropa, maka memasuki akhir kekuasaan Hindia Belanda jumlah penduduk berkebangsaan Eropa berada di atas jumlah penduduk berkebangsaan Cina. Menjadi menarik untuk diamati lebih lanjut, mengapa penduduk bangsa Eropa begitu antusias untuk tinggal dan menetap di kota Bandung setelah Bandung menyandang status sebagai sebuah gemeente. 
Perkembangan penduduk kota Bandung yang demikian pesat, dalam perkembangan selanjutnya meningkatkan pula kebutuhan atas tempat tinggal. Untuk itu pemerintah gemeente Bandung berupaya keras untuk dapat memenuhi kebutuhan akan permukiman ini, khususnya permukiman bagi penduduk berkebangsaan Eropa. Sejalan dengan kebijakan pembentukan gemeente Bandung yang cenderung diskriminatif, penataan permukiman di kota Bandung pun jelas-jelas diatur secara diskriminatif pula. Pemerintah gemeente Bandung dengan terang-terangan mengadakan pemisahan antara permukiman untuk orang Eropa, orang Cina, dan orang Timur asing lainnya, dan permukiman untuk kaum pribumi. Dengan kata lain, pemerintah gemeente Bandung pada saat itu menerapkan system socio-spatial segregation pada perancangan kota Bandung. Permukiman untuk orang Eropa terdiri dari rumah-rumah besar dan relatif modern. Komplek permukiman Eropa yang pertama kali direncanakan dan dibangun di Bandung adalah permukiman yang terletak di daerah Andir atau di sekitar lapangan terbang Andir saat itu. Karena letaknya yang berdekatan dengan lapangan terbang ini pulalah yang menjadikan pemukiman Eropa di sekitar Andir ini dikenal dengan nama fokkerhuis.

Menyusul pembangunan permukiman modern di daerah Andir, pemerintah gemeente bekerjasama dengan pihak swasta saat itu kemudian membangun permukimanpermukiman modern di daerah lainnya, seperti di daerah Kosambi, khususnya di sekitar halte Cikudapateuh, dan di sekitar Jalan Riau saat ini, khususnya di sekitar Oranje Plein, Merdekaweg sampai dengan Grote postweg. Berbeda dengan bangunan-bangunan perumahan yang dibangun di Andir dan Kosambi, bangunan-bangunan yang didirikan disekitar Oranje Plein bisa dikatakan jauh lebih mewah dan terdiri dari dua lantai bangunan. Pun begitu pula dengan jaringan jalan di simpanglima. Grote Postweg Bandung dirancang untuk 'impresi' gerbang masuk Kota Bandung saat itu dan jaringan jalan yang lain sebagai pelengkapnya.

\section{KESIMPULAN}

Sejarah pertumbuhan jaringan jalan menunjukkan bahwa pembangunan jaringan jalan bertujuan pada pelayanan daerah-daerah yang bersifat sosial, ekonomi dan politik. Pembangunan jaringan jalan baru ditentukan oleh kondisi tanah, jaringan jalan lama yang dapat dimanfaatkan dan batasan-batasan budaya setempat.

Dari kecenderungan pertumbuhan dan perkembangan yang terlihat serta keberadaan arsitektur kolonial yang tersisa, dapat dikatakan bahwa konfigurasi Simpanglima lahir sebagai konsekuensi dari perpotongan elemen jalan Anyer-Panarukan (Grote Postweg) dengan jalan tradisional (sekarang Jalan Sunda) dan penembusan jalan ke pabrik senjata PINDAD (sekarang Jalan Jenderal Gatot Subroto). Pembangunan jaringan jalan dan halte Kereta Api Cikudapateuh serta pergudangan tempat penyimpanan hasil perkebunan teh setempat telah mendorong konfigurasi Simpanglima khususnya Jalan Ahmad Yani ini bertumbuh. Pembangunan potongan Jalan Jenderal Gatot Subroto antara Jalan Ketapang dan Simpanglima telah menjadikan Jalan Jenderal Gatot Subroto konfigurasi jalan yang penting di Bandung dan melahirkan konfigurasi Simpanglima yang sekarang masih dapat kita lihat artefaknya. Untuk studi lebih lanjut, data tentang pertumbuhan jaringan jalan ini akan ditempatkan sebagai konfigurasi dinamis kawasan Simpanglima Bandung pada level atas.

Pertumbuhan bangunan yang tidak serentak telah melahirkan bentuk bangunan yang beraneka ragam disebabkan pengaruh faktor kontrol agen, teknologi dan gaya arsitek yang merencanakan bangunan tersebut. Ini terlihat pada pemecahan dua bangunan sudut di pangkal Jalan Asia Afrika dengan konsep bangunan pojok dan konsep bangunan dengan set back. Untuk studi lebih mendalam tentang aplikasi teori transformasi, data tentang pertumbuhan bangunan serta ruang luar yang terbentuk ini akan ditempatkan sebagai bentukan pada level bawah yang bersifat dependent terhadap pertumbuhan level jalan di atasnya.

Dari analisis dapat disimpulkan bahwa pertumbuhan fisik kota tidak dapat dikendalikan karena dugaan kurangnya kemampuan kontrol agen pos-kolonial. Seperti lazimnya, perubahan organisasi spasial selalu tertinggal dari pertumbuhan organisasi sosial. Kondisi ini ditambah lagi dengan munculnya pergeseran sistem kontrol agen melaui peraturan kota.

Dari analisis yang telah dipaparkan sebelumnya, penulis dapat berkesimpulan bahwa postulat Habraken menunjukkan kebenarannya dalam transformasi 
simpanglima dengan level jaringan jalan yang mendominasi dan menentukan hirarki pada level di bawahnya, dalam hal ini bangunan pembentuk simpanglima Bandung. Faktor politis dan perkembangan ekonomi melatarbelakangi hirarki, dalam hal ini dalam konteks kolonialisasi dimana inlander dengan segala saran dan prasarananya dikesampingkan dalam proses perancangan kota. Pada akhirnya, studi dalam konteks pos kolonialisasi ini diharapkan dapat memberi sumbangan revisi kebijakan kota yang terkait dengan kebijakan pemerintah kolonial.

\section{REFERENSI}

[1] Nas, Peter JM., Pratiwo (2000). Java and The Grote Postweg: La Grande Route.

[2] Habraken, N.John. (1997) . The Structure of the Ordinary, Form and Control in the Built Environment. Massachusets: MIT Press

[3] Voskuil, Robert P.G.A. (1997) . Bandung: Citra Sebuah Kota

[4] Kusno, A. (2000) . Behind the Postcolonial: Architecture, Urban Space and Political Cultures in Indonesia. London: Routledge

[5] Reitsma, SA. (1942). Bandoeng : The Mountain City of Netherlands India. G. Kolf \& Co Weltevreden (Batavia)

[6] Pramono, Sidik . (2008) . Ekspedisi Anjer Panaroekan. Jakarta: Kompas Gramedia.

[7] Dienaputra, Reiza D, (2005). Bandung 1906-1970: Studi tentang Perkembangan Ekonomi Kota. Kota Lama - Kota Baru: Sejarah Kota-Kota di Indonesia. 188-208. Yogyakarta: Penerbit Ombak

[8] Dana, Djefry W (1990) . Ciri Perancangan Kota Bandung. Jakarta: Gramedia Pustaka Utama 
